\title{
Dissociation between the brain target and respiratory capacity in critically ill patients. Authors' reply
}

Tommaso Mauri ${ }^{1,2^{*}} \mathbb{D}$, Elena Spinelli ${ }^{1}$, Jeremy R. Beitler ${ }^{3}$, Antonio Pesenti ${ }^{1}, 2$ and Daniel Brodie ${ }^{3}$

(c) 2020 Springer-Verlag GmbH Germany, part of Springer Nature

\section{Dear Editor,}

We thank Georgopoulos and Brochard for their letter on our review article [1]. They highlighted a few relevant points with which we agree.

Figure 1 in our review was introduced along the peer review process in response to a specific request from a reviewer. This figure was created as a new graph using equations for the metabolic hyperbola and numbers for the $\mathrm{PaCO}_{2}$ /ventilation correlations that are available in the literature [2] and also as open access content on the internet (see also the Online supplement). However, as the equations and numbers used to build our graphs are similar to those used for figure 4 in the review by Dr. Vaporidi et al. [3], the two figures ended up being very similar. We definitely should have acknowledged the resulting similarity in the legend by adding the relevant reference.

Along the same line, in the main text of our review, we presented the theory on the dissociation between brain and ventilation curves as already established knowledge, without attributing it to a specific source. We would like to acknowledge here that this theory is fully described in the review article by Vaporidi et al. [3], cited in our review as reference number 11 .

We are well aware that integrating physiological research into clinical practice builds on the shoulders of experts who dedicated their efforts to describing complex mechanisms and to develop comprehensive theories that

\footnotetext{
*Correspondence: tommaso.mauri@unimi.it

${ }^{1}$ Dipartimento di Anestesia, Rianimazione ed Emergenza-Urgenza,

Fondazione IRCCS Ca' Granda Ospedale Maggiore Policlinico, Università degli studi di Milano, Via F. Sforza 35, 20122 Milan, Italy
}

Full author information is available at the end of the article unify knowledge and foster clinical reasoning. Our work would be impossible without their countless contributions to the field.

\section{Electronic supplementary material}

The online version of this article (https://doi.org/10.1007/s00134-020-05984 -w) contains supplementary material, which is available to authorized users.

\section{Author details \\ ${ }^{1}$ Dipartimento di Anestesia, Rianimazione ed Emergenza-Urgenza, Fondazi- one IRCCS Ca' Granda Ospedale Maggiore Policlinico, Università degli studi di Milano, Via F. Sforza 35, 20122 Milan, Italy. ${ }^{2}$ Department of Pathophysiol- ogy and Transplantation, University of Milan, Milan, Italy. ${ }^{3}$ Center for Acute Respiratory Failure, Division of Pulmonary Allergy, and Critical Care Medicine, Columbia University College of Physicians and Surgeons/New York-Presbyte- rian Hospital, New York, NY, USA.}

\section{Compliance with ethical standards}

\section{Conflicts of interest}

ES and JRB don't have any conflict of interests to disclose. TM reports personal fees from Drager, Fisher and Paykel and Mindray, outside the submitted work. AP reports personal fees from Maquet, Novalung/Xenios, Baxter and Boehringer Ingelheim, outside the submitted work. DB reports grants from ALung technologies, personal fees from Baxter, personal fees from BREETHE, personal fees from Xenios, other from Hemovent, outside the submitted work.

\section{Publisher's Note}

Springer Nature remains neutral with regard to jurisdictional claims in published maps and institutional affiliations.

Accepted: 20 February 2020

Published online: 03 March 2020

\section{References}

1. Spinelli E, Mauri T, Beitler JR, Pesenti A, Brodie D (2020) Respiratory drive in the acute respiratory distress syndrome: pathophysiology, 
monitoring, and therapeutic interventions. Intensive Care Med. https:// doi.org/10.1007/s00134-020-05942-6

2. Tobin JM, Laghi F, Jubran A (2012) Ventilatory failure, ventilator support, and ventilator weaning. Compr Physiol 2:2871-2921
3. Vaporidi K, Akoumianaki E, Telias I, Goligher EC, Brochard L, Georgopoulos D (2020) Respiratory drive in critically ill patients: pathophysiology and clinical implications. Am J Respir Crit Care Med 201:20-32 